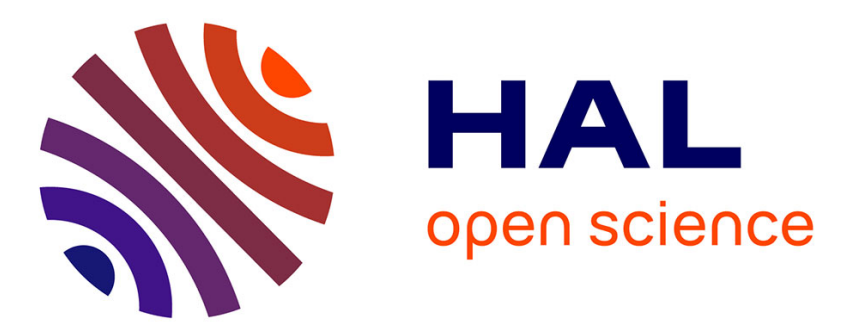

\title{
Sensitivity of Torque Control for Seven-phase BLDC Machine with One Opened Phase under Constraints on Voltage and Current
}

\author{
Duc Tan Vu, Ngac Ky Nguyen, Eric Semail
}

\section{- To cite this version:}

Duc Tan Vu, Ngac Ky Nguyen, Eric Semail. Sensitivity of Torque Control for Seven-phase BLDC Machine with One Opened Phase under Constraints on Voltage and Current. 2018 International Symposium on Power Electronics, Electrical Drives, Automation and Motion (SPEEDAM), Jun 2018, Amalfi, Italy. pp.142-148, 10.1109/SPEEDAM.2018.8445406 . hal-03083472

HAL Id: hal-03083472

https://hal.science/hal-03083472

Submitted on 19 Dec 2020

HAL is a multi-disciplinary open access archive for the deposit and dissemination of scientific research documents, whether they are published or not. The documents may come from teaching and research institutions in France or abroad, or from public or private research centers.
L'archive ouverte pluridisciplinaire HAL, est destinée au dépôt et à la diffusion de documents scientifiques de niveau recherche, publiés ou non, émanant des établissements d'enseignement et de recherche français ou étrangers, des laboratoires publics ou privés. 


\title{
Sensitivity of Torque Control for Seven-phase BLDC Machine with One Opened Phase under Constraints on Voltage and Current
}

\author{
Duc Tan Vu, Ngac Ky Nguyen, Eric Semail \\ Univ. Lille, Arts et Metiers ParisTech, Centrale Lille, HEI, EA 2697 - L2EP -Laboratoire d'Electrotechnique et d'Electronique de \\ Puissance, F-59000 Lille, France \\ E-mail: \{ductan.vu; ngacky.nguyen; eric.semail\}@ensam.eu
}

\begin{abstract}
This paper deals with control strategies when a sevenphase axial-flux brushless DC machine operates in one opencircuited phase fault by considering constraints on voltage and current. The constraints are related to the converter and machine design in terms of peak values of non-sinusoidal voltage and current. In addition, the sensitivity of the torque control on parameters of new imposed current references is analyzed under the base speed and in the flux-weakening region. The current references taking into account only first and third harmonics in healthy phases are proposed to ensure the torque optimization while phase currents and voltages are within their limits. The usefulness of the control strategies and the parameter analysis are verified by numerical results.
\end{abstract}

Keywords- 7-phase BLDC machine; open-phase fault; faulttolerant control; parameter sensitivity; torque control; constraints on non-sinusoidal voltage and current; flux-weakening.

\section{INTRODUCTION}

Multiphase machines have been utilized in variable-speed applications for a half of century and a significant rise in this area has been recorded in recent years because of the developments in some specific uses [1] and thanks to the advent of powerful processors. The design, modeling and control methods in healthy mode of operation are analyzed in [2]. One main advantage of multiphase machines is to have better fault-tolerance from faults of the power converter in comparison with their 3-phase counterparts $[3,4]$. There is a variety of studies concerning opencircuited faults in the operation of multiphase machines. A constant torque can be obtained by a reconfiguration of control if the types of faults are detected and localized by a methodology as proposed in [5]. Many strategies have been proposed to determine optimal current references to maximize torque with a given copper loss level when one or more phases of the machines are open-circuited.

In [6-8], the fundamental and third harmonic current components for the excitation in healthy stator phases are introduced to control five-phase permanent-magnet motors with trapezoidal back-EMFs in open-phase faults. In these studies, there are eight unknown variables in current expressions that need to be determined (for example by Fmincon in MATLAB). By this way, machines with seven or more phases need more variables, which makes current solutions more complicated and less accurate because optimization algorithms are usually sensitive to the number of variables. In [9], fault tolerant control strategies for a 7-phase machine using a vectorial multiphase description are verified with single and double open-circuit faults. However, these approaches have not considered the constraints on voltage and current of the drive system. These constraints play an important role in the sizing and cost of VSI as well as for the machine protection from thermal point of view. Besides, for wide speed-range applications such as electric vehicles or wind turbines, it is notable to take a flux-weakening strategy into account in the systems to meet the requirement of machine-converter voltage limits. In [10], a variable speed control method including voltage and current limits is applied to a 5-phase permanent magnet synchronous generator but with sinusoidal back-EMFs only. In [11], the authors have proposed different control strategies for odd and even phase sinusoidal machines in one opened-phase faults. New current references for the degraded modes ensure the same magnetomotive force (MMF) as in healthy mode. However, these methods are only for sinusoidal back-EMF machines and the issue on maximum currents and voltages have not been considered. In [12], an interesting approach is proposed, for 5-phase sinusoidal backEMF machines, by defining a weighting factor which either optimizes copper losses in healthy operation or limits phase currents satisfying a required torque in case of one open-circuit faults, including the flux-weakening operation. However, the currents obtained by this approach contain high frequency components which limit the range of speed.

In this paper, based on [11], control strategies for one opened-phase fault is proposed to control the 7-phase brushless DC axial-flux machine with double identical rotors. The first and third harmonics of back-EMF are considered; therefore, the first and third harmonic currents are imposed to generate the torque. Simpler new current references are proposed with only three variables in the operation under base speed (with the control method of maximum torque per ampere (MTPA)) and four variables in the flux-weakening operation. Impacts of these variables are analyzed to optimize the mean torque amplitude and minimize the torque ripple while satisfying the constraints on peak values of non-sinusoidal current and voltage of the system, including flux-weakening region. 

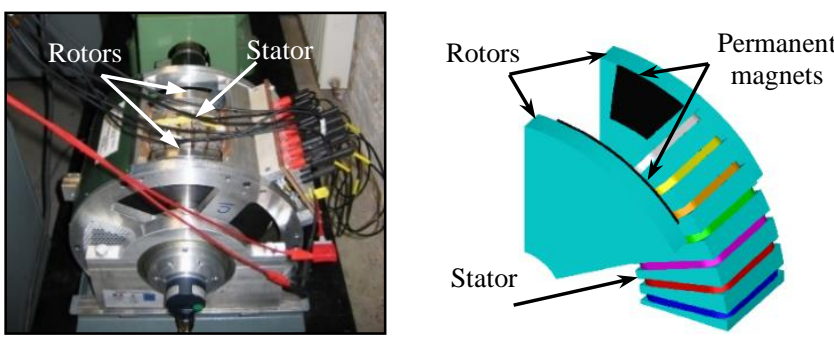

Fig. 1. The 7-phase axial-flux double rotor BLDC machine.

The paper is organized as follows: Section 2 describes the model and parameters of the considered machine. The control strategy in a single open-circuit fault is demonstrated in Section 3. Section 4 analyzes the impacts of variations in the current parameters on the torque production.

\section{Multi-PHASE MACHINE MODELING AND PARAMETERS}

The design of the 7-phase BLDC machine is proposed in [13, 14] with axial flux and double identical rotors as shown in Fig. 1. To identify the machine model, these following assumptions are considered: 7 phases are equally shifted and wye-connected; the machine has trapezoidal back-EMFs; the saturation of the magnetic circuits is not taken into account in the calculation of the back-EMFs and fluxes.

The voltage vector and torque can be written as follows:

$$
\begin{aligned}
& \vec{v}=R \vec{\imath}+\Lambda \frac{d \vec{\imath}}{d t}+\vec{e} \\
& T_{m}=\frac{\vec{e} \cdot \vec{\imath}}{\Omega}=\vec{e}_{n} \cdot \vec{\imath}
\end{aligned}
$$

where $\vec{v}, \vec{\imath}$ and $\vec{e}$ are the 7-dimensional stator voltage, current and back-EMF vectors respectively; $R$ is the stator resistance of each phase; $\Lambda$ is a 7 by 7 stator inductance matrix; $T_{m}$ is the torque and $\Omega$ is the rotating speed of the machine; $\vec{e}_{n}=$ $\left(e_{a n}, e_{b n}, e_{c n}, e_{d n}, e_{e n}, e_{f n}, e_{g n}\right)$ is the speed-normalized backEMF vector.

In fact, the speed-normalized back-EMFs of the machine contain many harmonics as expected by analyzing Fig. 2. The RMS values of the first and third harmonics account for the highest proportions while those of higher harmonics can be neglected [9]. For simplicity of current and torque expressions, the back-EMFs are assumed to contain only the first and third harmonics as expressed in equation (3).

$e_{j n}=E_{m 1} \sin \left(\omega t-(j-1) \frac{2 \pi}{7}\right)+E_{m 3} \sin \left(3\left(\omega t-(j-1) \frac{2 \pi}{7}\right)\right)$

where $e_{j n}$ is the speed-normalized back-EMF of phase $j ; E_{m 1}$, $E_{m 3}$ and $k_{e}=E_{m 3} / E_{m 1}$ are the amplitudes and the ratio of the first and third harmonics of the back-EMF respectively; $\omega=p \Omega$ is the electric speed of the machine.

The electrical parameters of the 7-phase machine and converter for validating the efficiency of the control strategies and analyzing the sensitivity of current parameters are shown in Table 1.
TABLE I. ELECTRICAL PARAMETERS OF CONVERTER AND MACHINE

\begin{tabular}{|l|c|}
\hline \multicolumn{1}{|c|}{ Parameter } & Value \\
\hline Stator resistance $R(\Omega)$ & 1.4 \\
\hline Phase inductance $L(\mathrm{mH})$ & 10.1 \\
\hline Mutual inductance $M_{1}(\mathrm{mH})$ & 3.1 \\
\hline Mutual inductance $M_{2}(\mathrm{mH})$ & -1.05 \\
\hline Mutual inductance $M_{3}(\mathrm{mH})$ & -5.3 \\
\hline Number of pole pairs p & 3 \\
\hline $\begin{array}{l}\text { Speed-normalized amplitude of } 1^{\text {st }} \text { harmonic back-EMF } E_{m 1} \\
\text { (V/rad/s) }\end{array}$ & 2.38 \\
\hline $\begin{array}{l}\text { Speed-normalized amplitude of } 3^{\text {rd }} \text { harmonic back-EMF } E_{m 3} \\
\text { (V/rad/s) }\end{array}$ & 0.45 \\
\hline DC bus voltage $V_{D C}(\mathrm{~V})$ & 200 \\
\hline Maximum peak current $(\mathrm{A})$ & 7.5 \\
\hline
\end{tabular}

In this machine, the amplitude of the third harmonic backEMFs equals approximately $19 \%$ of the first harmonic ones $\left(k_{e}=E_{m 3} / E_{m 1}=0.19\right)$. The converter is supplied by a DC bus voltage of $200 \mathrm{~V}$ and the allowed peak phase current is 7.5 A.

\section{Control Method in Degraded Mode}

Without loss of generality, it can be assumed that the opencircuited fault happens in phase $a$. The control strategy is adapted for other open-circuited phases. When one phase is opencircuited, it is necessary to keep continuous operations of the drive with acceptable performances. However, the imposed current references in healthy mode are often unsuitable for the faulty cases in some applications such as offshore wind energy systems due to mechanical resonance created by torque ripples; therefore, these currents need to be modified [9]. In [11], the authors have proposed new sinusoidal current references for healthy phases of sinusoidal back-EMF seven-phase machines in a single opened-phase fault. These sinusoidal currents are assumed to have the same amplitude which is, for the same torque, $23 \%$ higher than in normal operation. Nevertheless, the constraints on current and voltage and methods for trapezoidal back-EMF machines have not been considered.

In this paper, new non-sinusoidal current references for the non-sinusoidal back-EMF seven-phase machine are proposed. The first and third harmonic currents are considered to contribute to the torque production. The new current references in the natural frame are denoted by $i_{b}^{\prime}, i_{c}^{\prime}, i_{d}^{\prime}, i_{e}^{\prime}, i_{f}^{\prime}$ and $i_{g}^{\prime}$ and expressed by equations (4-9).

$$
\begin{aligned}
& i_{b}^{\prime}=I_{m 1} \sin \left(\omega t+\varphi_{b}+\varphi_{1}\right)+I_{m 3} \sin \left(3\left(\omega t+\varphi_{b}+\varphi_{3}\right)\right) \\
& i_{c}^{\prime}=I_{m 1} \sin \left(\omega t+\varphi_{c}+\varphi_{1}\right)+I_{m 3} \sin \left(3\left(\omega t+\varphi_{c}+\varphi_{3}\right)\right) \\
& i_{d}^{\prime}=I_{m 1} \sin \left(\omega t+\varphi_{d}+\varphi_{1}\right)+I_{m 3} \sin \left(3\left(\omega t+\varphi_{d}+\varphi_{3}\right)\right) \\
& i_{e}^{\prime}=-i_{b}^{\prime} \\
& i_{f}^{\prime}=-i_{c}^{\prime} \\
& i_{g}^{\prime}=-i_{d}^{\prime}
\end{aligned}
$$




$$
T=I_{m 1} E_{m 1}\left\{\begin{array}{c}
\left(k_{1} \cos \left(\omega t-\frac{5 \pi}{7}\right)+k_{3} \cos \left(3\left(\omega t-\frac{5 \pi}{7}\right)\right)\right)\left(\sin \left(\omega t+\varphi_{b}+\varphi_{1}\right)+k_{i} \sin \left(3\left(\omega t+\varphi_{b}+\varphi_{3}\right)\right)\right) \\
-\left(k_{1} \cos (\omega t)+k_{3} \cos (3(\omega t))\right)\left(\sin \left(\omega t+\varphi_{c}+\varphi_{1}\right)+k_{i} \sin \left(3\left(\omega t+\varphi_{c}+\varphi_{3}\right)\right)\right) \\
+\left(k_{1} \cos \left(\omega t-\frac{9 \pi}{7}\right)+k_{3} \cos \left(3\left(\omega t-\frac{9 \pi}{7}\right)\right)\right)\left(\sin \left(\omega t+\varphi_{d}+\varphi_{1}\right)+k_{i} \sin \left(3\left(\omega t+\varphi_{d}+\varphi_{3}\right)\right)\right)
\end{array}\right\}
$$

where $I_{m 1}$ and $I_{m 3}$ are the amplitudes of the first and third harmonic currents respectively; $\varphi_{b}, \varphi_{c}$ and $\varphi_{d}$ are constant initial phase angles of phase $b, c$ and $d$ respectively, determined by the method in [11]; $\varphi_{1}$ and $\varphi_{3}$ are adjustable phase angles of the first and third harmonics of currents.

The proposed current references with the same amplitude enable an equal distribution of copper losses in all healthy phases of the machine. Hence, the requirements of the machine design are significantly simplified. The above references also satisfy the assumption of the wye connection because the sum of all instantaneous currents is zero. Besides, the waveform of current in each phase with MTPA control is like the corresponding experimental back-EMF as shown in Fig. 2. This similarity allows the machine to obtain the maximum torque.

From equations (2-9), the generated torque could be expressed in equation (10) in which $k_{1}=2 \sin (3 \pi / 7)$ and $k_{3}=$ $2 k_{e} \sin (9 \pi / 7)$ are constants determined from the machine parameters; $k_{i}=I_{m 3} / I_{m 1}$ is the ratio between the third and first harmonics of the currents. The torque-time and torque-speed characteristics are functions of $I_{m 1}, k_{i}, \varphi_{1}$ and $\varphi_{3}$. Adjustments of these parameters result in changes in the average torque and torque pulsation of the machine. This study investigates the impacts of these parameters on: the torque (average and ripple values), the speed range, the maximal values of current and voltage.

Additionally, the limits on voltage and current of the machine are shown in equations (11-12) and the absolute values of phase voltages are calculated as in equations (13-18).

$$
\begin{aligned}
& {\left[\left|i_{b}^{\prime}\right| ;\left|i_{c}^{\prime}\right| ;\left|i_{d}^{\prime}\right| ;\left|i_{e}^{\prime}\right| ;\left|i_{f}^{\prime}\right| ;\left|i_{g}^{\prime}\right|\right] \leq I_{\max }} \\
& {\left[\left|v_{b}^{\prime}\right| ;\left|v_{c}^{\prime}\right| ;\left|v_{d}^{\prime}\right| ;\left|v_{e}^{\prime}\right| ;\left|v_{f}^{\prime}\right| ;\left|v_{g}^{\prime}\right|\right] \leq V_{\max }}
\end{aligned}
$$

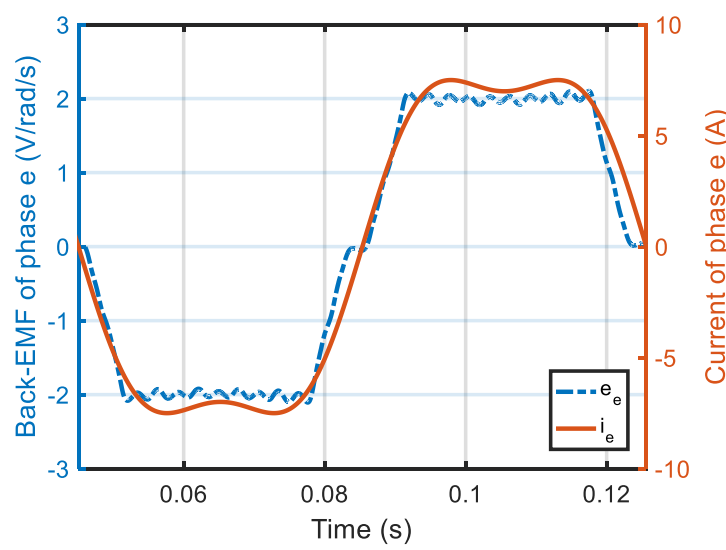

Fig. 2. Current reference with MTPA control and experimental back-EMF in phase $e$ of the machine at $26 \mathrm{rad} / \mathrm{s}$.

$$
\begin{aligned}
& \left|v_{b}^{\prime}\right|=\left|\begin{array}{c}
R i i_{b}^{\prime}+L \frac{d i_{b}^{\prime}}{d t}+M 1\left(\frac{d i_{c}^{\prime}}{d t}\right) \\
+M 2\left(\frac{d i_{d}^{\prime}}{d t}+\frac{d i_{g}^{\prime}}{d t}\right)+M 3\left(\frac{d i_{e}^{\prime}}{d t}+\frac{d i_{f}^{\prime}}{d t}\right)+e_{b}
\end{array}\right| \\
& \left|v_{c}^{\prime}\right|=\left|\begin{array}{c}
2 i i_{c}^{\prime}+L \frac{d i_{c}^{\prime}}{d t}+M 1\left(\frac{d i_{b}^{\prime}}{d t}+\frac{d i_{d}^{\prime}}{d t}\right) \\
+M 2\left(\frac{d i_{e}^{\prime}}{d t}\right)+M 3\left(\frac{d i_{f}^{\prime}}{d t}+\frac{d i_{g}^{\prime}}{d t}\right)+e_{c}
\end{array}\right| \\
& \left|v_{d}^{\prime}\right|=\left|\begin{array}{c}
i_{d}^{\prime}+L \frac{d i_{d}^{\prime}}{d t}+M 1\left(\frac{d i_{c}^{\prime}}{d t}+\frac{d i_{e}^{\prime}}{d t}\right) \\
+M 2\left(\frac{d i_{b}^{\prime}}{d t}+\frac{d i f_{f}^{\prime}}{d t}\right)+M 3\left(\frac{d i_{g}^{\prime}}{d t}\right)+e_{d} \\
R i_{e}^{\prime}+L \frac{d i_{e}^{\prime}}{d t}+M 1\left(\frac{d i_{d}^{\prime}}{d t}+\frac{d i_{f}^{\prime}}{d t}\right) \\
+M 2\left(\frac{d i_{c}^{\prime}}{d t}+\frac{d i_{g}^{\prime}}{d t}\right)+M 3\left(\frac{d i_{b}^{\prime}}{d t}\right)+e_{e} \\
R i_{f}^{\prime}+L \frac{d i_{f}^{\prime}}{d t}+M 1\left(\frac{d i_{e}^{\prime}}{d t}+\frac{d i_{g}^{\prime}}{d t}\right) \\
+M 2\left(\frac{d i_{d}^{\prime}}{d t}\right)+M 3\left(\frac{d i_{c}^{\prime}}{d t}+\frac{d i_{b}^{\prime}}{d t}\right)+e_{f} \\
R i_{g}^{\prime}+L \frac{d i_{g}^{\prime}}{d t}+M 1\left(\frac{d i_{f}^{\prime}}{d t}\right) \\
\left|v_{f}^{\prime}\right| \\
+M 2\left(\frac{d i_{b}^{\prime}}{d t}+\frac{d i_{e}^{\prime}}{d t}\right)+M 3\left(\frac{d i_{c}^{\prime}}{d t}+\frac{d i_{d}^{\prime}}{d t}\right)+e_{g}
\end{array}\right|
\end{aligned}
$$

where $I_{\max }$ and $V_{\max }$ are current and voltage limits according to the converter and machine parameters; $L$ is the self-inductance of each phase; $M_{1}, M_{2}$, and $M_{3}$ are mutual inductances between one phase and its adjacent and non-adjacent phases of the machine.

In the paper, neglecting the impact of a homopolar voltage component, the value of $V_{\max }$ is equal to a half of the DC bus voltage $V_{D C}$ in the Pulse Width Modulation technique. The value of $I_{\max }$ can be determined by the peak value of instantaneous currents related to VSI components or the maximum thermal current depending on temperature of windings. According to the machine parameters in Table 1 , the verification of the control strategies is carried out with $V_{\max }=100 \mathrm{~V}$ and $I_{\max }=7.5 \mathrm{~A}$. This value of $I_{\max }$ is only for a short-term operation and will decrease in a long-term use according to the thermal constraint of the machine. Operations under and above the base speed (37 $\mathrm{rad} / \mathrm{s}$ ) are analyzed in next sections. Fmincon function in MATLAB is an optimizer that can estimate the parameters of the current references to maximize the torque and respect the constraints on peak values of non-sinusoidal current and voltage.

\section{ANALYSIS OF EFFECTS OF CURRENT PARAMETERS}

\section{A. Operation below the base speed}

Under the base speed (for example at $20 \mathrm{rad} / \mathrm{s}$ ), the phase currents are controlled to be maximal (corresponding to a 
maximum torque) while the phase voltages are under their limit. The optimal values of the amplitude $I_{m 1}$, ratio $k_{i}$ and initial phasors $\left(\varphi_{1}, \varphi_{3}\right)$ of the current references are determined by Fmincon and remain unchanged during this operation $\left(I_{m 1}=\right.$ $\left.8.6 A, k_{i}=0.19, \varphi_{1}=\varphi_{3}=0 \mathrm{rad}\right)$. An analysis using the torque expression (10) to investigate the impacts of the current parameters on the machine torque control will be conducted in this section. For simplicity, only the initial phase angle of the third harmonics $\varphi_{3}$ is considered and denoted by $\varphi$ while that of the first harmonics is nullified $\left(\varphi_{1}=0\right)$. In addition, when one of the above parameters of the current references is being considered, the others are constant and equal to their optimal values. Variations of each current parameter $\left(I_{m 1}, \varphi\right.$ or $\left.k_{i}\right)$ within its range and consequent changes in the phase currents and the torque generation at $20 \mathrm{rad} / \mathrm{s}$ are derived as follows:

\section{1) Effects of the first harmonic current amplitude $\left(I_{m 1}\right)$}

In the current equations (4-9), $I_{m 1}$ is proportional to the peak value of phase currents of the machine. To guarantee the constraint on current, the value of $I_{m 1}$ must be less than or equal to the optimal value of $8.6 \mathrm{~A}$ which is determined by Fmincon. Besides, the relationships between the average torque, torque ripple and $I_{m 1}$ are easily analyzed by using the torque equation (10). When $I_{m 1}$ increases from 0 to $10 \mathrm{~A}$, the average torque also linearly rises from 0 to about $70 \mathrm{Nm}$ while the torque ripple value does not change and remains equal to $7.2 \%$. It means that $I_{m 1}$ has no effect on the torque ripple but it is proportional to the average torque.

\section{2) Effects of the current phase $\left(\varphi_{3}=\varphi ; \varphi_{1}=0\right)$}

In Fig. 3, when $\varphi$ varies within the interval $[-\pi / 2 ; \pi / 2]$, enabling sine functions of phase angles in equation (10) to take on their full range of values $[-1 ; 1]$, the peak value of the nonsinusoidal healthy phase currents varies between $7.5 \mathrm{~A}$ and 10.2 A. The lowest peak current is $7.5 \mathrm{~A}$ when $\varphi$ is zero, which means that the constraint on current is satisfied only at that point. Furthermore, the waveform of the currents is also modified. Fig. 4 shows that there are major changes in the torque ripple (from $7 \%$ to $63 \%$ ) but minor variations in the average torque in terms of $\varphi$. The optimal value of $\varphi$ is zero because at this point, the average torque is maximum at $59.6 \mathrm{Nm}$ while the torque pulsation is minimum at $7.2 \%$.

\section{3) Effects of the current ratio $\left(k_{i}\right)$}

The range of the current ratio $k_{i}=I_{m 3} / I_{m 1}$ is supposed to increase from 0 to 1 . The variation of $k_{i}$ affects the peak value of phase currents as shown in Fig. 5. The value of $k_{i}$ must be equal to $k_{e}=E_{m 3} / E_{m 1}=0.19$ so that the peak value of all phase currents is equal to its limit $I_{\max }=7.5 \mathrm{~A}$ and the control method MTPA is implemented. In addition, Fig. 6 shows that the torque ripple dramatically increases when $k_{i}$ varies far away from the value of $k_{e}$. The torque average undergoes a moderate increase when $k_{i}$ gains from 0 to 1 .

\section{4) Summary of the functioning under the base speed}

From the analyses above, the average torque is sensitive to $I_{m 1}$ while the torque ripple is significantly affected by $\varphi$ and $k_{\mathrm{i}}$.
It can be seen that $k_{\mathrm{i}}=k_{\mathrm{e}}=0.19, I_{m 1}=8.6 \mathrm{~A}$ and $\varphi=0 \mathrm{rad}$ are the optimal solution of the proposed current references. At these values, the highest average torque equals $59.6 \mathrm{Nm}$ (approximately $80 \%$ of the heathy torque as shown in Fig. 11) with a small torque ripple $(7.2 \%)$ in one opened-phase fault.

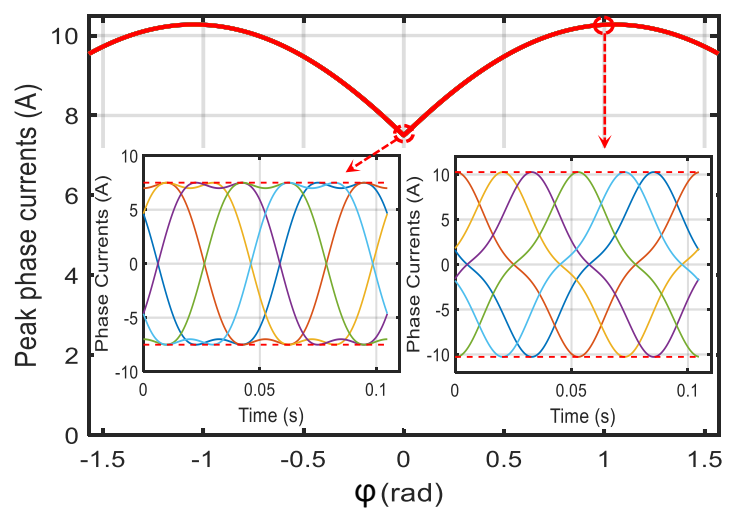

Fig. 3. Effect of $\varphi=\varphi_{3}$ on the peak value of healthy phase currents when phase $a$ is open-circuited and phase current waveforms at $\varphi=0 \operatorname{rad}$ and $\varphi=1 \operatorname{rad}$.

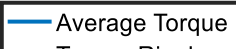

- - Torque Ripple

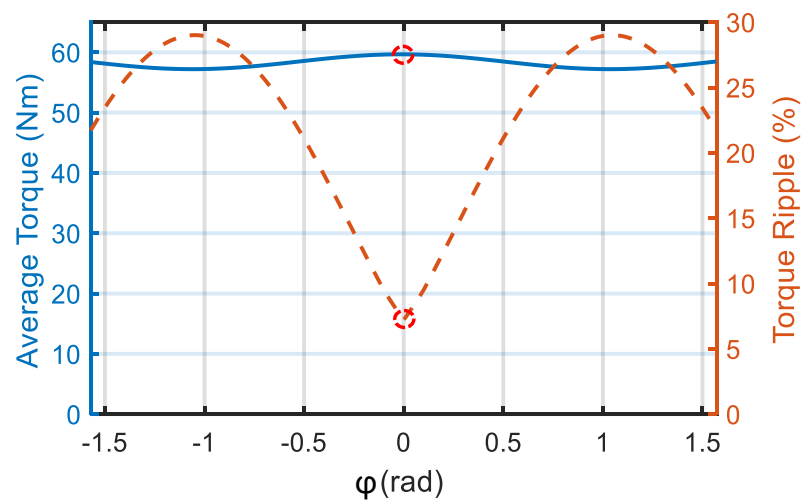

Fig. 4. Impact of $\varphi=\varphi_{3}$ on the average torque and torque ripple when phase $a$ is open-circuited.

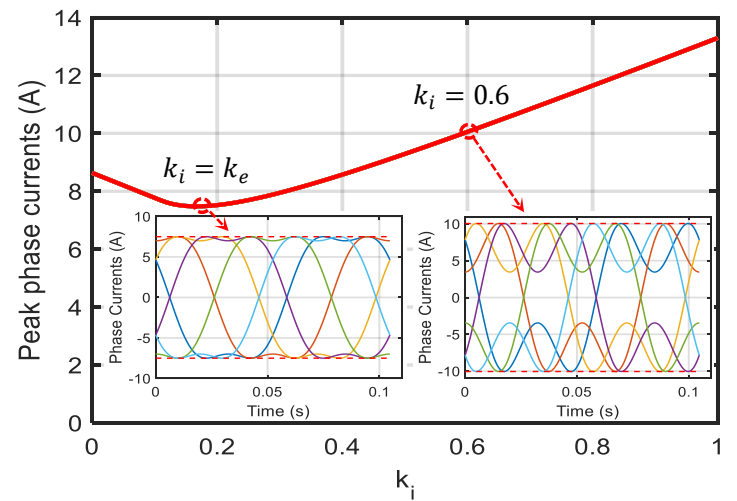

Fig. 5. Effect of $k_{i}=I_{m 3} / I_{m 1}$ on the peak value of the healthy phase currents when the phase $a$ is open-circuited and, in addition, phase current waveforms at $k_{i}=k_{e}=0.19$ and $k_{i}=0.6$. 


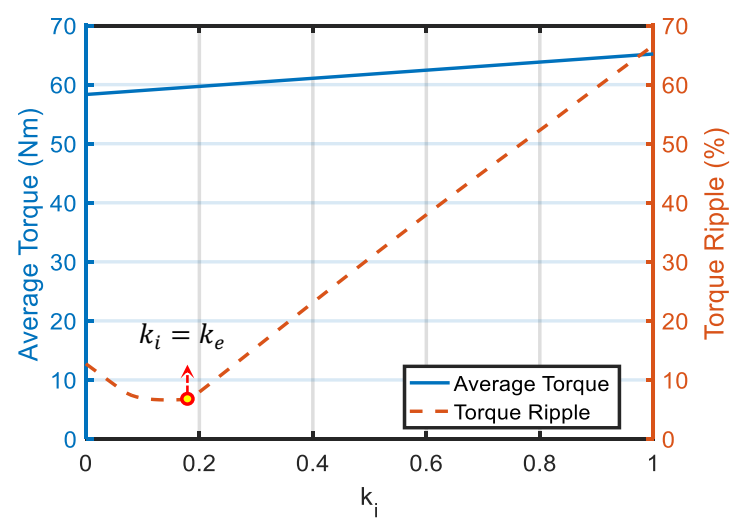

Fig. 6. Impact of $k_{i}=I_{m 3} / I_{m 1}$ on the average torque and torque ripple when phase $a$ is open-circuited.

\section{B. The flux-weakening operation}

When the speed exceeds the base speed $(37 \mathrm{rad} / \mathrm{s})$, the machine turns into the flux-weakening operation. To keep the phase voltages within the constraint value (Fig. 7) and obtain a maximal average torque, the absolute value of the d-axis currents must increase while that of the q-axis currents need to decrease, keeping the peak phase currents equal to $I_{\max }$ (Fig. 8). As a result, in natural frame, the first harmonic amplitude $I_{m 1}$, current ratio $k_{i}$ and initial phases $\varphi_{1}$ and $\varphi_{3}$ of phase currents need to be adapted accordingly at every speed over the base speed. In general, each of the current parameters can be a constant or variable. Because of 4 parameters keeping constant or changing, there are 16 possibilities for the variations of phase currents. However, it is necessary to have at least one adjustable variable among 4 parameters, hence 15 options are available to vary the current parameters to allow the machine to operate in the fluxweakening region. In these options, only cases with variations of $\varphi_{1}$ and $\varphi_{3}$ (for example, strategy 1 as defined in Table 2) can make the peak current value of the healthy phases equal to $I_{\max }$ in the flux-weakening operation. In the previous section, it has been shown that parameters $\varphi$ and $\mathrm{k}_{i}$ affect seriously the peak phase current and the torque ripple. Therefore, strategy 1 produces unacceptable torque ripple increasing from $7.2 \%$ under base speed to $60 \%$ at $50 \mathrm{rad} / \mathrm{s}$ due to adjustments of $\varphi_{1}$ and $\varphi_{3}$ (Fig. 9). Therefore, because $I_{m 1}$ has no effect on the torque ripple, a simple solution in which only $I_{m 1}$ is varied to respect the voltage constraint and minimize the torque ripple is proposed and named strategy 2 and defined in Table 2 . With the strategy 2 , the peak value of healthy phase currents changes from $I_{\max }=7.5 \mathrm{~A}$ to lower values in the flux-weakening region while their waveforms are identical, for example, the peak value decreases from $7.5 \mathrm{~A}$ at 20 $\mathrm{rad} / \mathrm{s}$ to $2 \mathrm{~A}$ at $45 \mathrm{rad} / \mathrm{s}$ in Fig. 10. In Fig. 11, the average torques of strategies 1 and 2 are the same under the base speed and equal to $80 \%$ of the value in healthy mode. In the flux-weakening region, the torque of the strategy 2 is slightly lower than that of the strategy 1. Nevertheless, in Fig. 12, the torque ripple of strategy 2 at all speeds is tiny and unchanged at $7.2 \%$ much smaller than that of strategy 1 . These results can be compared with a classical strategy producing no torque ripple: in Figs. 11 and 12 , the torque ripple is completely eliminated but the average torque is equal to only $58 \%$ of the healthy mode as discussed in [15]. In this strategy, current references in $\mathrm{d}-\mathrm{q}$ frames are imposed as constant values.

TABLE II. TWO STRATEGIES IN FLUX-WEAKENING OPERATION

\begin{tabular}{|c|c|c|c|c|}
\hline Strategy & $\boldsymbol{I}_{\boldsymbol{m} \mathbf{1}}(\mathrm{A})$ & $\boldsymbol{k}_{\mathbf{i}}$ & $\boldsymbol{\varphi}_{\mathbf{1}}(\mathbf{r a d})$ & $\boldsymbol{\varphi}_{\mathbf{3}}(\mathbf{r a d})$ \\
\hline 1 & variable & variable & variable & variable \\
\hline 2 & variable & 0.19 & 0 & 0 \\
\hline
\end{tabular}

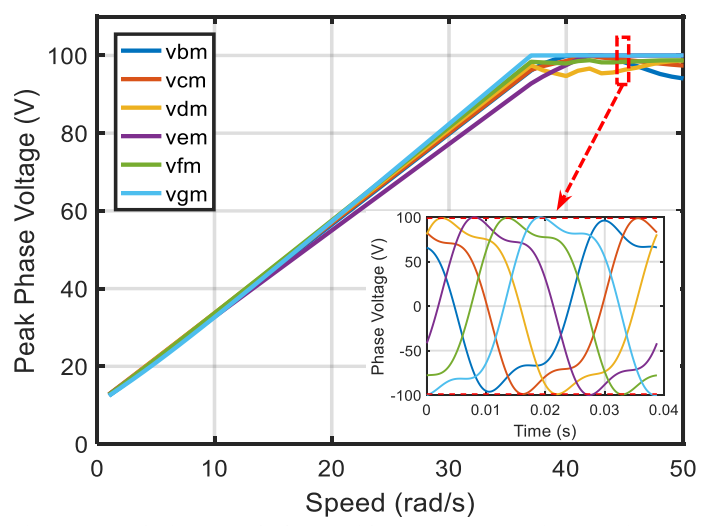

Fig. 7. Voltage-speed characteristics and instantaneous phase voltage at $45 \mathrm{rad} / \mathrm{s}$ over the base speed ( $37 \mathrm{rad} / \mathrm{s}$ ) when phase $a$ is open-circuited with strategy 1.

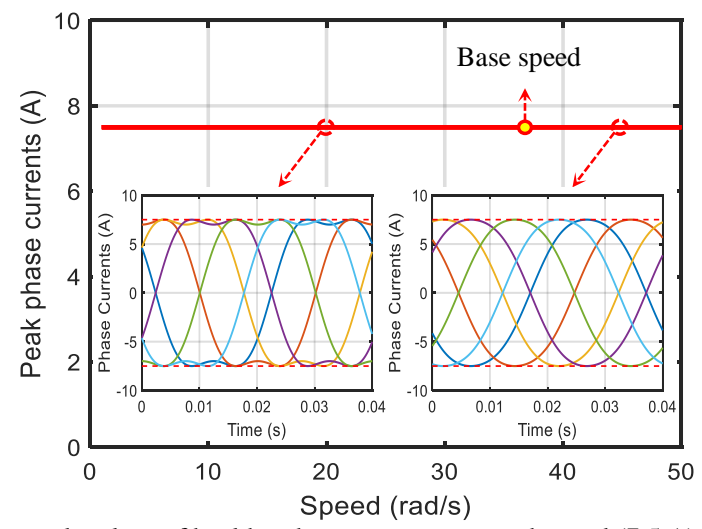

Fig. 8. The peak values of healthy phase currents are unchanged (7.5 A) at speeds over the base speed ( $37 \mathrm{rad} / \mathrm{s}$ ) when phase $a$ is open-circuited with strategy 1.

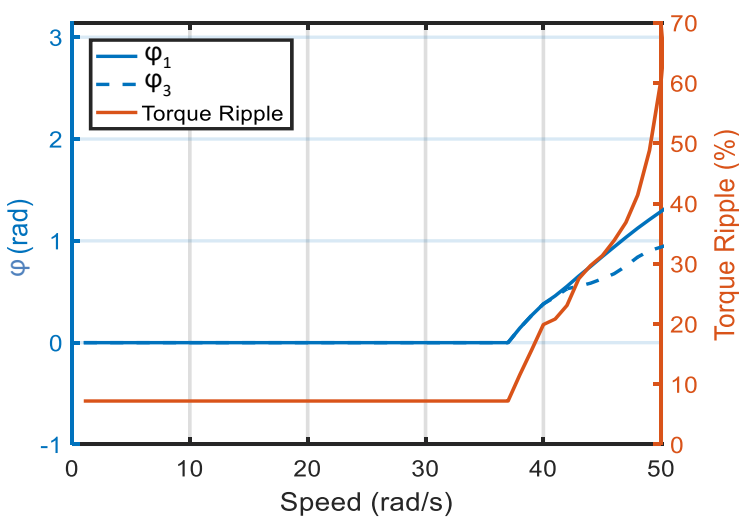

Fig. 9. Initial phases $\left(\varphi_{1}, \varphi_{3}\right)$ and torque ripple when phase $a$ is open-circuited with strategy 1 . 


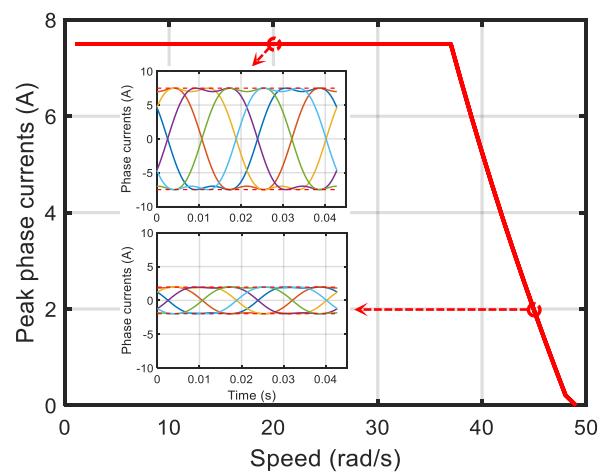

Fig. 10. The peak phase currents vs speed and phase currents at $20 \mathrm{rad} / \mathrm{s}$ and 45 $\mathrm{rad} / \mathrm{s}$ (the base speed is $37 \mathrm{rad} / \mathrm{s}$ ) when phase $a$ is open-circuited with strategy 2 .

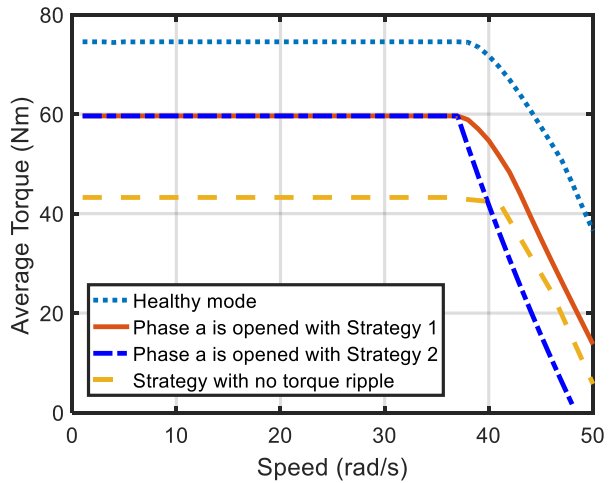

Fig. 11. Average torques in healthy mode and when phase $a$ is open-circuited with different strategies.

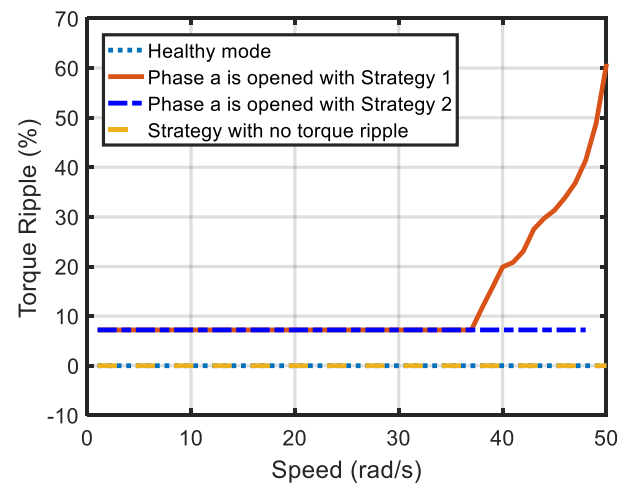

Fig. 12. Torque ripples in healthy mode and when phase $a$ is open-circuited with different strategies.

\section{V.CONCLUSIONS}

For a 7-phase BLDC machine with non-sinusoidal backEMFs, the paper has analyzed control strategies imposing two harmonics of phase currents to generate torque and guarantee the constraints on peak values of non-sinusoidal voltage and current. When the torque ripple is not imposed to zero, the proposed current references enable the machine to produce a torque in oneopened phase fault equal to $80 \%$ of the heathy torque with a low torque ripple of $7 \%$. On the contrary, if the torque ripple is totally nullified, the average torque probably drops to $58 \%$ of the healthy mode. In addition, effects of parameters of the current

references on torque control have been analyzed in the operation under the base speed and in the flux-weakening region. The system is simulated by MATLAB to verify the usefulness of the control strategies. In future, the methods will be implemented to the experimental system.

\section{REFERENCES}

